\title{
Passive 3D motion optical data in shaking table tests of a SRG-reinforced masonry wall
}

\author{
Gerardo De Canio ${ }^{* 1}$, Gianmarco de Felice ${ }^{2 a}$, Stefano De Santis ${ }^{2 b}$, Alessandro \\ Giocoli $^{1 \mathrm{~b}}$, Marialuisa Mongelli ${ }^{1 \mathrm{~b}}$, Fabrizio Paolacci ${ }^{2 \mathrm{a}}$ and Ivan Roselli ${ }^{1 \mathrm{~b}}$ \\ ${ }^{1}$ Qualification of Materials and Components Laboratory, ENEA, Via Anguillarese 301 - 00123 Rome, Italy \\ ${ }^{2}$ Department of Engineering, Roma Tre University, Via Vito Volterra 62 - 00146 Rome, Italy
}

(Received December 5, 2014, Revised July 4, 2015, Accepted July 10, 2015)

\begin{abstract}
Unconventional computer vision and image processing techniques offer significant advantages for experimental applications to shaking table testing, as they allow the overcoming of most typical problems of traditional sensors, such as encumbrance, limitations in the number of devices, range restrictions and risk of damage of the instruments in case of specimen failure. In this study, a 3D motion optical system was applied to analyze shake table tests carried out, up to failure, on a natural-scale masonry structure retrofitted with steel reinforced grout (SRG). The system makes use of wireless passive spherical retro-reflecting markers positioned on several points of the specimen, whose spatial displacements are recorded by near-infrared digital cameras. Analyses in the time domain allowed the monitoring of the deformations of the wall and of crack development through a displacement data processing (DDP) procedure implemented ad hoc. Fundamental frequencies and modal shapes were calculated in the frequency domain through an integrated methodology of experimental/operational modal analysis (EMA/OMA) techniques with 3D finite element analysis (FEA). Meaningful information on the structural response (e.g., displacements, damage development, and dynamic properties) were obtained, profitably integrating the results from conventional measurements. Furthermore, the comparison between 3D motion system and traditional instruments (i.e., displacement transducers and accelerometers) permitted a mutual validation of both experimental data and measurement methods.
\end{abstract}

Keywords: 3D optical measurement; passive markers; steel reinforced grout; shaking table; structural damage monitoring; modal analysis

\section{Introduction}

Visual tracking systems have been applied to structural monitoring with interesting results since the early 1990s (Stephen et al. 1993). Recent studies investigated the potentialities of optical techniques and image processing for detecting structural displacements, reaching submillimetric accuracy thanks to the technological advances and the improvement of data processing methods

*Corresponding author, Ph.D., E-mail: gerardo.decanio@enea.it

${ }^{\mathrm{a}}$ Professor

${ }^{\mathrm{b}} \mathrm{Ph} . \mathrm{D}$.

Copyright @ 2016 Techno-Press, Ltd. 
(Mas et al. 2012, Yoneyama et al. 2007). Computer vision and image processing techniques were also applied to shaking table testing (Beraldin et al. 2004, Lunghi et al. 2012) to remedy some drawbacks of conventional instrumentation, such as encumbrance, limitations in the number of sensors, range restrictions, and risk of damage of the devices. Moreover, a typical limitation of displacement devices, such as LVDTs and laser sensors, is due to their capacity of providing accurate data in only one direction. Consequently, the need of locating three sensors for tri-axial acquisition at each measurement point causes more difficult and time-spending set-up, also taking into account the usual range and encumbrance of conventional sensors.

On the contrary, passive light-based optical systems are able to acquire up to more than a hundred small retro-reflecting spherical markers, providing a very flexible and effective description of 3D motion with much easier installation. In such systems, the cameras acquire only a narrow band of radiation wavelengths retro-reflected by the markers, which helps the recognition algorithms optimizing resolution and computational power. In addition, though still quite expensive in this kind of applications, digital image technologies steadily progress in terms of performance improvement at lowering cost. In this promising context, a passive light-based optical 3D motion capture system, named 3DVision, was installed at ENEA Casaccia Research Center and specifically configured at the purpose of tracking the displacements of a large number of specimen points under dynamic load in shaking table testing (De Canio et al. 2013, Calderini et al. 2014).

In this paper, the 3DVision was used for evaluating shaking table tests on a full-scale masonry wall retrofitted with steel reinforced grout. The experimental study is devoted to investigate the effectiveness of externally bonded reinforcement systems with mortar-based composite materials for the safeguarding of existing structures against earthquakes (de Felice et al. 2014).

A displacement data processing (DDP) method was developed for optimizing data noise reduction in order to obtain an estimation of velocity and acceleration in addition to trajectories. This effort was justified to explore the markers potentiality to avoid the installation of 6 sensors ( 3 accelerometers and 3 displacement sensors) for each measurement point in tests where tri-axial data are needed and encumbrance problems are remarkable. The implemented DDP method aims at providing meaningful information on the structural response (e.g., displacements, damage development, and dynamic properties), to be integrated with conventional measurements. The fundamental frequencies and the modal shapes are calculated in the frequency domain through an integrated methodology of experimental/operational modal analysis (EMA/OMA) techniques with the help of 3D finite element models. The 3DVision measurements are compared to those from traditional instruments (i.e., displacement transducers and accelerometers) to provide a mutual validation of measured data and acquisition methods as well.

\section{Laboratory testing}

\subsection{Mock-up description}

The tested mock-up was a full-scale C-shaped ashlar tuff-masonry model made up of a façade and two non-indented lateral walls (Fig. 1(a)). It represents a typical macroelement in Italian historical masonry structures and constitutes a very vulnerable situation during seismic loading, in which a rocking motion if the façade is often activated leading to its complete out-of-plane overturning.

After a first shaking table session (Al Shawa et al. 2012), the damaged structure was repaired 
and retrofitted with Steel Reinforced Grout (SRG), that comprises a unidirectional textile made of ultra-high tensile strength steel cords embedded into a natural hydraulic lime mortar (De Santis et al. 2015), as shown in Fig. 1(b).

A detail of SRG-reinforced specimen is shown in Fig. 2(a). Both the horizontal SRG strips installed on the façade are linked to the lateral walls by connectors, which cross the façade and are bonded with hydraulic lime mortar to the lateral walls (Fig. 2(b)). Thanks to the use of an inorganic matrix, the proposed retrofitting solution is suitable for applications to historical substrates, thus appearing promising for the structural protection of architectural heritage (Valluzzi et al. 2014). To date, research studies have been mainly carried out to provide a mechanical characterization under tension (De Santis and de Felice 2015a) and to investigate the reinforcement-to-substrate bond performance (Razavizadeh et al. 2014, De Santis and de Felice 2015b), demonstrating both the durability and the effective cord-to-mortar interlocking of the steel textiles within the mortar matrix (Ascione et al. 2015). The shake table study described in this paper aims at providing a deeper understanding of their actual effectiveness in case of earthquake.

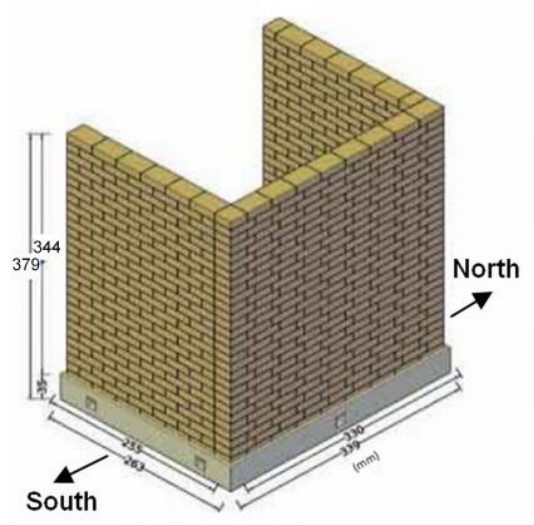

(a) Unreinforced specimen

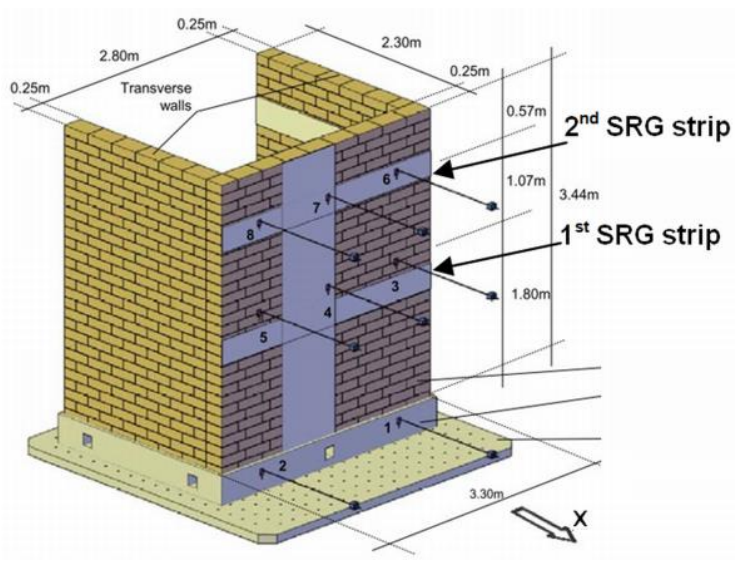

(b) SRG-reinforced specimen

Fig. 1 Specimen geometry

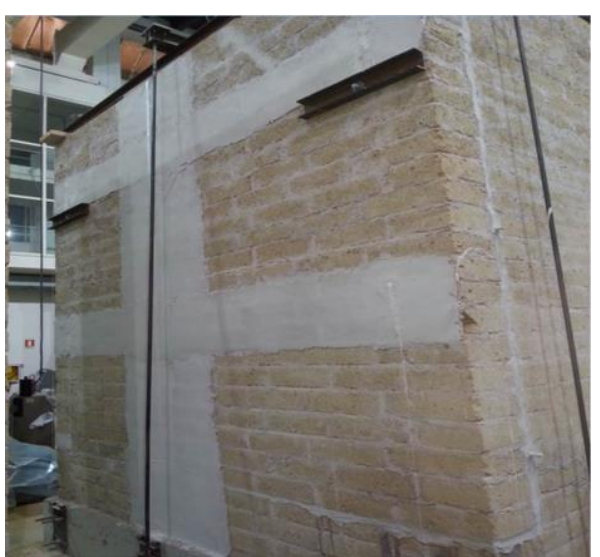

(a) Façade

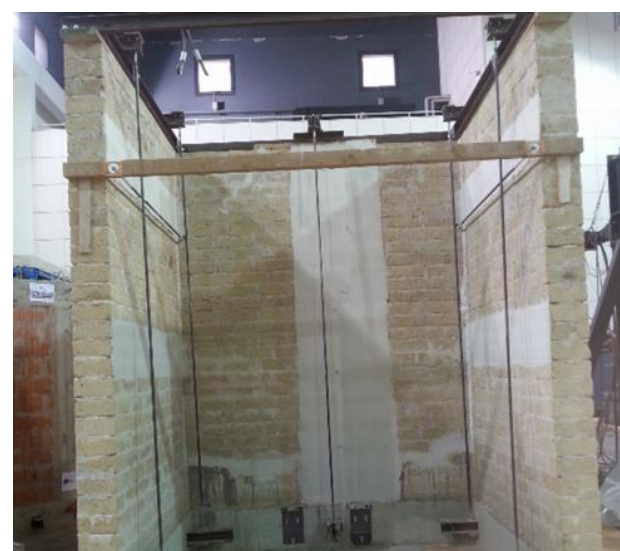

(b) Back view

Fig. 2 Details of the SRG-reinforced specimen 


\subsection{Experimental program}

The experimental program consisted in two test sessions executed before and after the installation of the SRG reinforcement. Seismic inputs were selected among the records of the main Italian earthquakes of the last 30 years: Irpinia (1980), Umbria-Marche (1997) (Fig. 3), L'Aquila (2009) and Emilia (2012). In both sessions, the signals were applied in direction normal to the façade, scaled with increasing factors up to failure. After each series with the same scale factor, the specimen was excited by a white noise input (random test) at $0.05 \mathrm{~g}$ for modal identification.

In order to compare the damaging potential of the different input signals, the Velocity Spectrum Intensity (VSI) was considered (Elenas 2013, Ye et al. 2013). It was calculated starting from the general equation for the VSI

$$
\mathrm{VSI}=\int_{T_{1}}^{T_{2}} S v(T, \xi) d T
$$

where $S v$ is the velocity spectrum, $T$ is the period, and $\xi$ is the critical damping (the usual value $\xi=5 \%$ was used). The considered limits of the integral of Eq. (1) were $T_{1}=0.0625 \mathrm{~s}$ and $T_{2}=0.2 \mathrm{~s}$, corresponding to the $5-16 \mathrm{~Hz}$ frequency range $\left(\mathrm{VSI}_{5-16}\right)$, in which a preliminary simulation with finite elements (that will be described in the following) indicated the first modal frequencies with relevant mass participation in $x$ and $y$ directions (see section 3.1). The $\mathrm{VSI}_{5-16}$ values obtained for the considered seismic inputs are illustrated in Fig. 4.

\subsection{Instrumentation and test set-up}

The seismic tests were performed at the ENEA Casaccia research center, provided with a shake table, whose main technical characteristics are listed in Table 1.

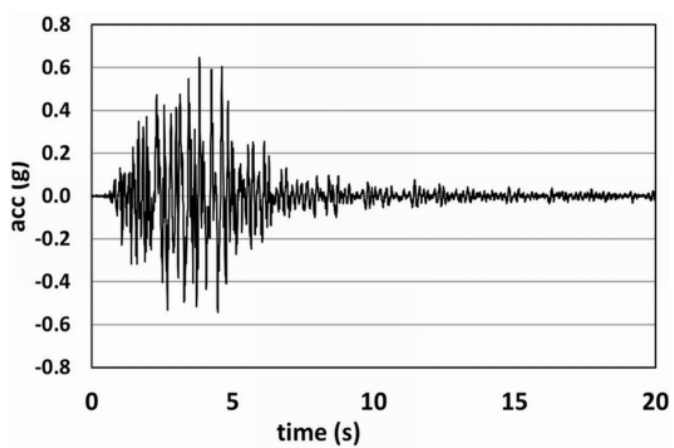

Fig. 3 Input R1168EW based on UmbriaMarche earthquake of September 1997

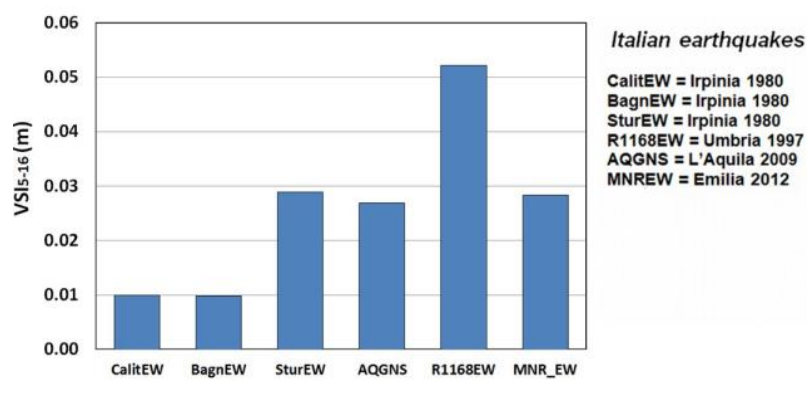

Fig. 4 Comparison of the main Italian earthquakes since 1980 in terms of at $\mathrm{VSI}_{5-16}$

Table 1 Main specifications of the shaking table used in the present study

\begin{tabular}{cccccc}
\hline \hline $\begin{array}{c}\text { Table size } \\
(\mathrm{m})\end{array}$ & $\begin{array}{c}\text { Degrees of } \\
\text { Freedom }\end{array}$ & $\begin{array}{c}\text { Frequency Range } \\
(\mathrm{Hz})\end{array}$ & $\begin{array}{c}\text { Maximum } \\
\text { Acceleration } \\
(\mathrm{g})\end{array}$ & $\begin{array}{c}\text { Maximum Velocity } \\
(\mathrm{m} / \mathrm{s})\end{array}$ & $\begin{array}{c}\text { Maximum } \\
\text { Displacement } \\
(\mathrm{m})\end{array}$ \\
\hline $4 \times 4$ & 6 & $0-50$ & 3.0 & 0.5 & 0.25 \\
\hline
\end{tabular}


Eight wire displacement transducers and eight accelerometers were installed on the façade to measure its out-of-plane response and on the reinforced concrete foundation to record the seismic input at its base (De Santis et al. 2015). A steel frame was built in front of the façade as a stiff reference where to attach the wire transducers housings. Finally, a protection net was added to the mock-up to avoid the façade crashing down after the collapse and damaging the instrumentation and the reference frame Fig. 5(d).

In addition to this traditional instrumentation, the 3DVision was used to acquire displacement data during the shaking table tests. It is a 3D light-based system provided with 9 near infrared (NIR) digital cameras. A CMOS sensor with resolution of 4 megapixels $(2352 \times 1728)$ is mounted in each NIR camera. The lens field of view (FOV) is $26.5 \mathrm{deg} \times 19.6 \mathrm{deg}$. Full-frame acquisition mode is available up to $370 \mathrm{fps}$ (or Hz), but partialised scanning mode allows to reach $2000 \mathrm{~Hz}$. In the present experimental study, the sampling frequency was $200 \mathrm{~Hz}$. Each camera is equipped with a strobe provided with powerful surface-mount light emitting diodes (LEDs) emitting NIR light in order to illuminate the field of view as evenly as possible. Spherical wireless retro-reflecting markers with a diameter of $25 \mathrm{~mm}$ are fixed to reflect the NIR radiation. On-board processors extract markers centers and radii, which are triangulated and processed on the host PC by the motion capture software in order to obtain the trajectories of the markers (more details on data processing are provided in section 4.1).

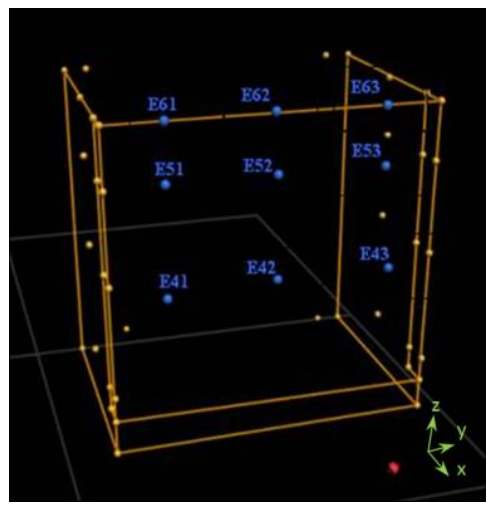

(a) Façade

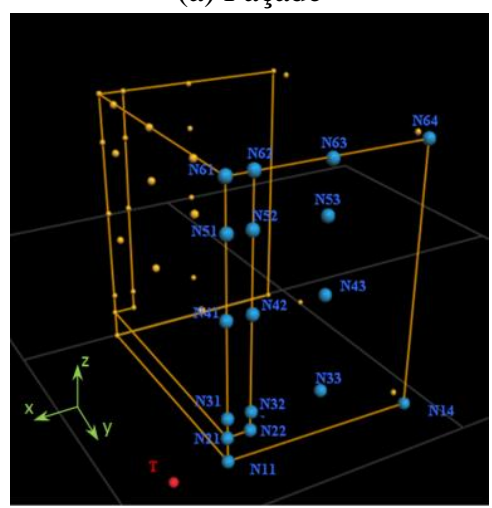

(c) North wall

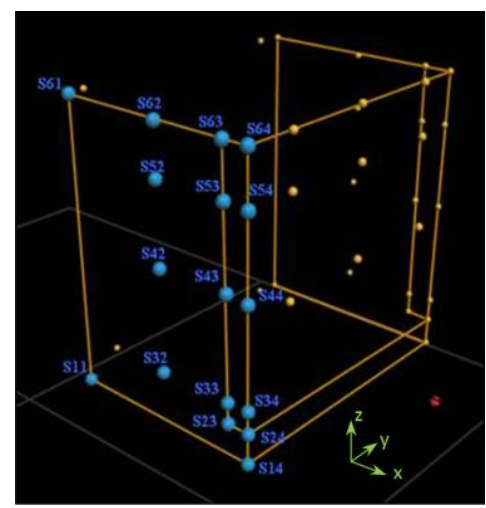

(b) South wall

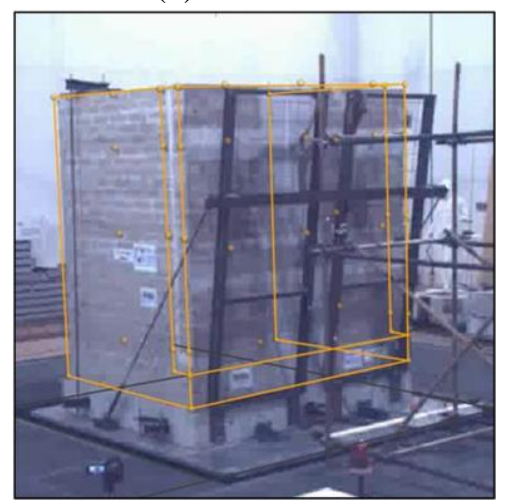

(d) 3D overlay with synchronized video

Fig. 5 Positions of 3DVision markers on the specimen 
Professional tripods were utilized for positioning the cameras in a way that each marker was visible by at least two cameras. On the structure under test, 48 markers were located in the positions shown in Figs. 5(a)-(c). Markers on the south wall are labelled with S, those on the north wall are labelled with N, while the ones on the façade are labelled with E. The markers E41, E42, E43, E51, E52 and E53 on the façade were placed at the same position of the traditional displacement wire transducers and accelerometers to allow comparisons.

Before the beginning of shaking table tests, ambient vibration was recorded by a velocimeter located atop the SRG-reinforced structure for passive horizontal to vertical spectral ratio (HVSR) ambient noise method. The recordings were collected with a 24-bit SL06/SARA data-logger equipped with three $2 \mathrm{~Hz}$ geophones. The north-south and east-west components were oriented in $x$ and $y$ directions respectively.

\section{Preliminary analyses}

\subsection{Preliminary FEA}

A preliminary finite element analysis (FEA) was performed to provide a first approximate assessment of the dynamic behavior of the unreinforced structure before the experimental tests in order to guide the data processing (especially for the optimization of filtering internal parameters) and to better interpret the results of the experimental modal analysis for the detection of the actual dynamic properties of the specimen. The C-shaped structure was meshed with 2530 solid Hexa elements and 4032 nodes. The structural continuity between the façade and the lateral walls was simulated by 1D rod elements. The Young modulus of the masonry was estimated from the elastic properties of tuff units and mortar joints as $E_{m}=1700 \mathrm{~N} / \mathrm{mm}^{2}$. Modal shapes, frequencies and mass participation rates were calculated (Table 2). The first two modes show relevant mass participation in $y$ and $x$ directions respectively. In particular, the first modal shape (Fig. 6(a)) is characterized prevalently by an antiphased oscillation of the rear lateral walls, while the second one (Fig. 6(b)) involves predominantly the out-of-plane deformation of the façade. As a first estimate, the modal frequencies of the reinforced model were increased by $10 \%$ taking into account a slight stiffening effect of the SRG strips.

\subsection{Preliminary monitoring with ambient noise}

The dynamic behavior of the undamaged SRG-reinforced structure was preliminarily examined by analyzing data acquired for 20 minutes by a velocimeter put on top of the mock-up before the beginning of shaking table tests. The HVSR ambient noise method (Gallipoli et al. 2009) was applied for an estimate of the fundamental frequency in both horizontal directions $x$ and $y$ separately. The observed first mode was at $8.8 \mathrm{~Hz}$ (Fig. 7(b)) and the second one was at $14.1 \mathrm{~Hz}$ (Fig. 7(a)). The mismatch between the frequencies measured with the velocimeter and those estimated by the finite element simulation (Table 2) is in the order of $20 \%$ and $10 \%$ for the first and the second modes, respectively. Such difference depends on the simplifications of the finite element model, which did not take into account some details of the reinforced specimen, such as its damage state, the actual position of the SRG strips (which may lead to an overestimate of the out-of-plane stiffness of the façade) and the effect of the vertical steel rods at the lateral walls (which are likely to produce a certain degree of stiffening affecting the first mode). 
Table 2 FEM modal frequencies and mass participation for the first two modes

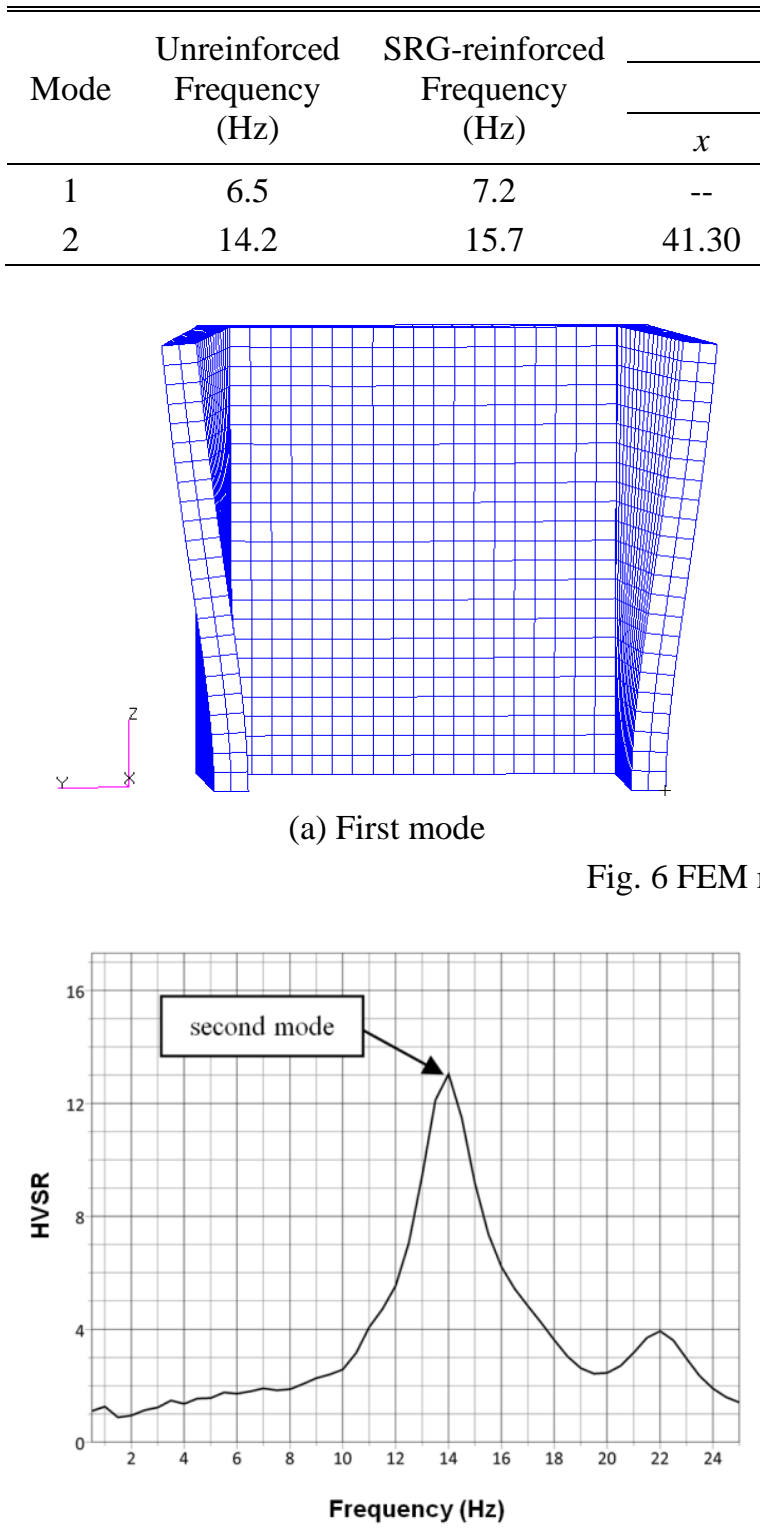

(a) $x$ direction

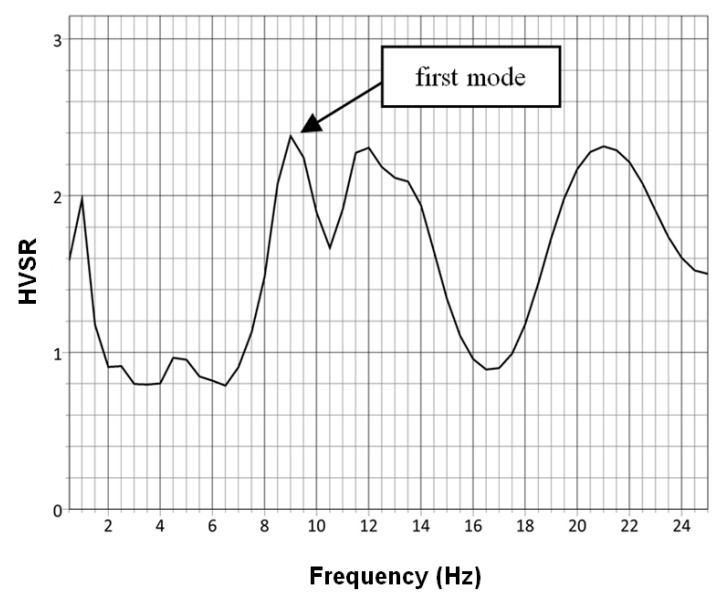

(b) $y$ direction

Fig. 7 HVSR curves for the horizontal components

\section{Data processing}

The methods used to process displacement recordings are described in this section. Data acquired by the 3DVision system were analyzed to derive trajectories, velocities and accelerations of all the monitored points, as well as the dynamic properties of the specimen (Fig. 8). 


\subsection{Displacements}

The 3D displacements were obtained starting from the trajectories of the markers. To calculate the trajectories, the centroid of each marker was first calculated (in each picture) in terms of 2D image coordinates (pixel units). Centroids are 2D circles fitted around the center of intensity of each grayscale blob identified as a marker. Subpixel interpolation was performed through brightness and circularity thresholds that determine the pixels to be considered for centroid fitting (Vicon 2006). Then, a dynamic and a static calibration processes were carried out. The former provided the NIR camera orientations and consisted in acquiring a wand moved by an operator inside the tracking volume (i.e., the volume viewed by all the cameras, which includes the shake table and is about $4 \mathrm{~m}$ high above it). The calibration wand was provided with 5 markers aligned along two orthogonal directions, whose relative positions were known to the 3DVision acquisition software. Such acquisition was processed by the system through reverse triangulation algorithms to extract cameras mutual positions. The static calibration process was used to define the coordinate system and consisted in a further acquisition of the wand placed on the ground, with the markers aligned along the desired $x$ and $y$ axis directions (one of the markers of the wand was taken as axis origin). Once the two calibration acquisitions were performed, recordings from different cameras were combined through a traditional triangulation algorithm applied to the centroids of the markers to reconstruct their position in the 3D volume. Finally, Reconstructed markers trajectories were exported to ASCII format and post-processed in the time and frequency domains, to provide information on the dynamic behavior of the model and to monitor the evolution of the structural damage throughout the shaking table tests.

The displacement data processing (DDP) procedure developed within this study was based on the Savitzky-Golay (SG) smoothing filter (Savitzky and Golay 1964) for the noise reduction of displacement data. The SG smoothing filter affects the frequency response of data by producing a series of spectral depressions controlled by the internal parameters $\mathrm{n}$ and $\mathrm{m}$ (representing the fitting polynomial degree and the moving window width, respectively) (Candan and Inan 2014). In the present study, the optimal values $n=4$ and $m=29$ were found to minimize the data noise without affecting the frequency range of interest (below $16 \mathrm{~Hz}$, as indicated by preliminary FEA).

The accuracy of a traditional displacement sensor is typically characterized as a percentage of its full-stroke range (Webster 1999). Consequently, the larger the displacements that must be measured, the wider the range that must be chosen for the devices, which entails larger inaccuracy in terms of expected absolute maximum error. The nominal accuracy of the wire transducers used in this study was $0.15 \%$ of full-stroke $(380 \mathrm{~mm})$, corresponding to an expected maximum absolute error of $0.6 \mathrm{~mm}$. Possible stretching and non-linear effects may cause a further error, consisting in an underestimate of the actual displacement. Differently, since 3DVision is a positioning system and not a displacement measurement system, its error is theoretically independent from the motion of the marker (Moeslund and Granum 2001), making it particularly suitable for applications to shake table tests on full-scale specimens, in which large displacements need to be measured. In this study, the error of 3DVision was calculated in static conditions (with stationary markers) as the root-mean-square (RMS) position error. It was slightly different for each marker, because it substantially consisted in a triangulation error, which depends on the distances and the view angles of the observing cameras (Hartley and Zisserman 2003), and did not change passing from static to dynamic conditions nor with the amount of the recorded displacement.

Having this in mind, the geometrical configuration of the cameras around the shaking table (Fig. 9) was planned to find a compromise between visibility of markers and accuracy in the 


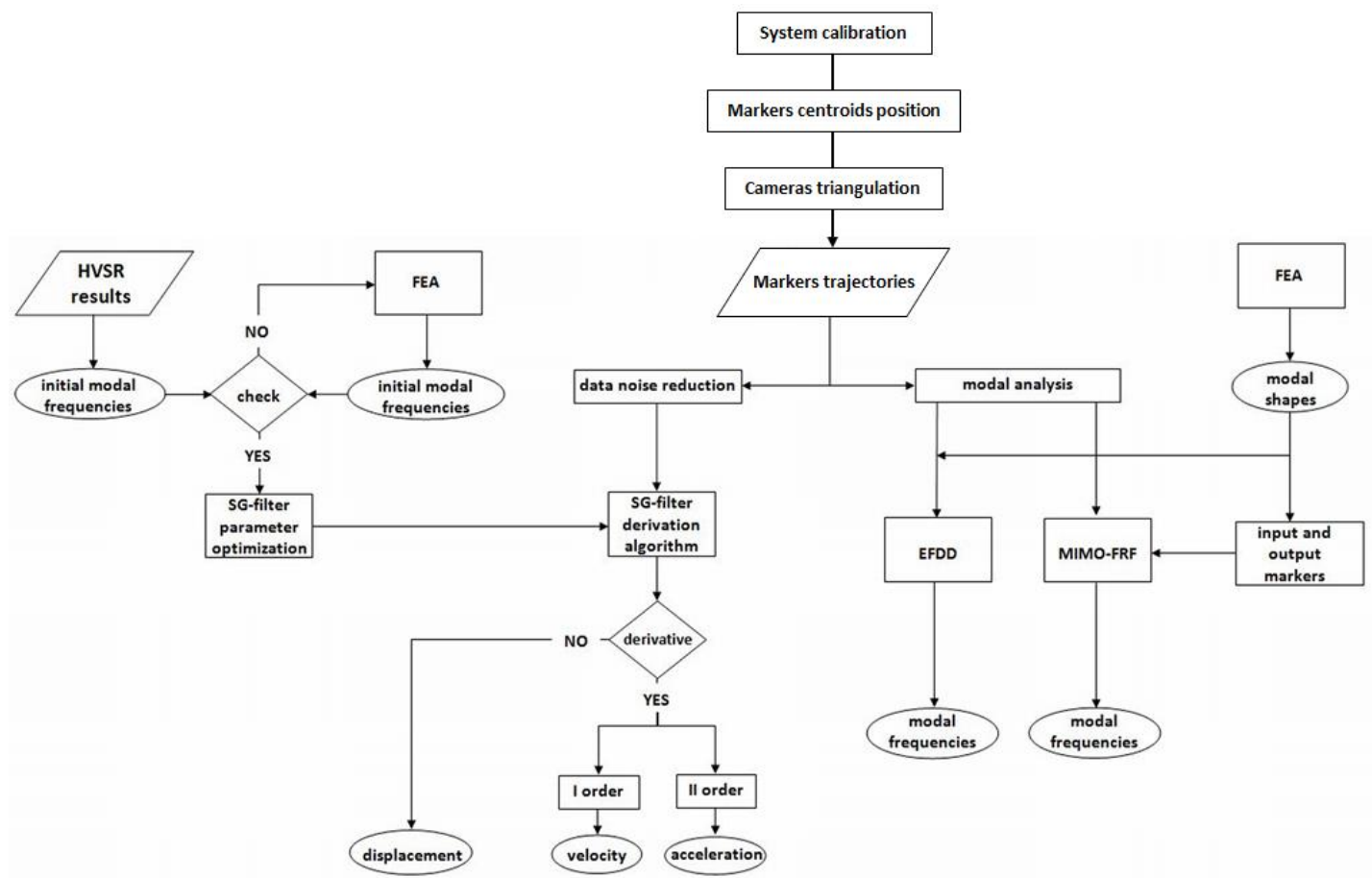

Fig. 8 Flowchart that describes the procedure of displacement data processing (DDP) implemented in the present paper in order to obtain the motion parameters and the modal frequencies

Table 3 Mean RMS error of markers positions

\begin{tabular}{ccc}
\hline \hline \multirow{2}{*}{ Direction } & \multicolumn{3}{c}{$\begin{array}{c}\text { Mean RMS error } \\
(\mathrm{mm})\end{array}$} \\
\cline { 2 - 4 } & Raw & SG-filtered $^{*}$ \\
\cline { 2 - 4 }$y$ & 0.07 & 0.06 \\
$z$ & 0.10 & 0.07 \\
& 0.07 & 0.06 \\
\hline
\end{tabular}

*SG-filter parameters are $n=4$ and $m=29$

seismic input direction ( $x$ direction) and a mean RMS error in the order of $0.1 \mathrm{~mm}$ was achieved (Table 3). The application of the SG smoothing filter with the selected internal parameters led to an improvement of accuracy with a mean RMS error in the order of 0.06-0.07 mm.

Fig. 10 shows a displacement time-history measured by a marker and by a corresponding (same position on the specimen) wire transducer in input direction (normal to the façade). A general good agreement was found, with a mismatch of up to $0.5 \mathrm{~mm}$ only in the displacement peaks. Nevertheless, transducers recorded the displacement of the façade only in its out-of-plane direction, while the 3DVision provided the whole spatial deformed configuration reached during earthquake motion. The behavior (opening-closing) of the connections between the façade and the lateral walls was also monitored by the markers located on both sides of the joint at different heights. 

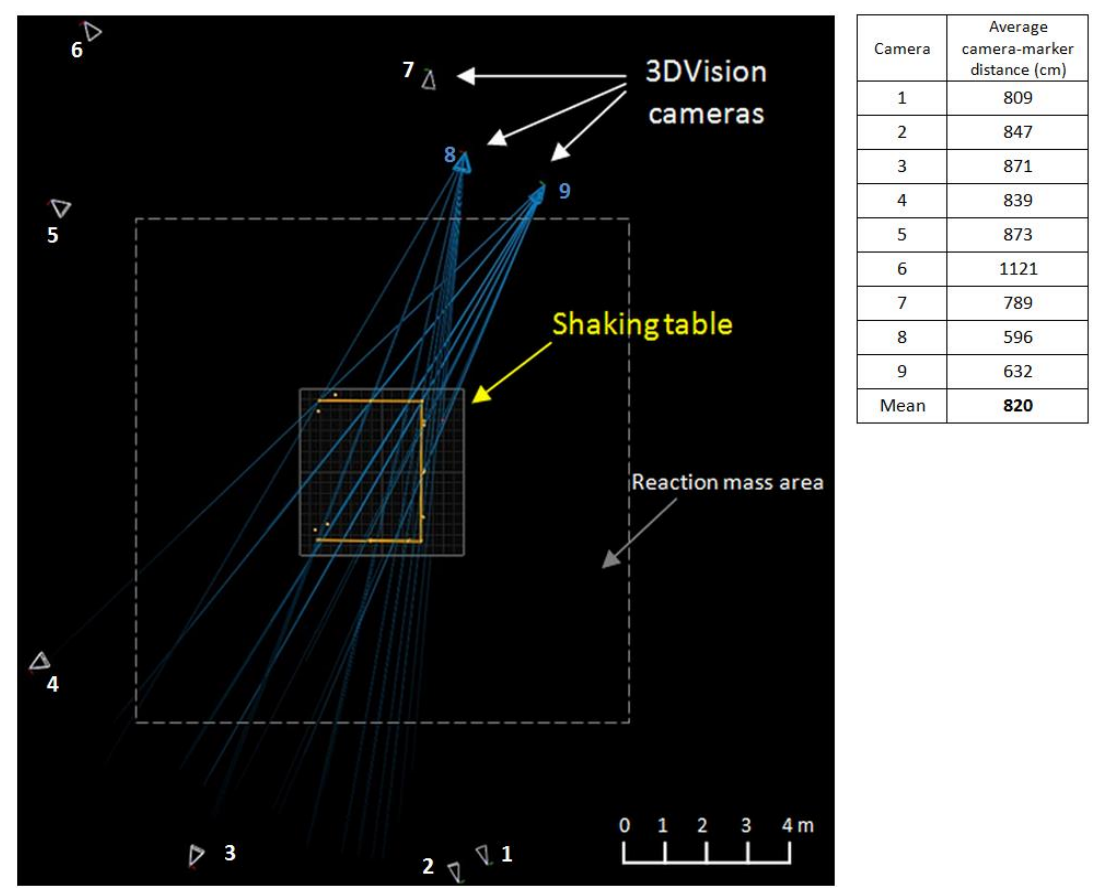

Fig. 9 Top view of the markers wireframe on the shaking table and 3DVision cameras positions: example of triangulation of two selected cameras rays (in blue)

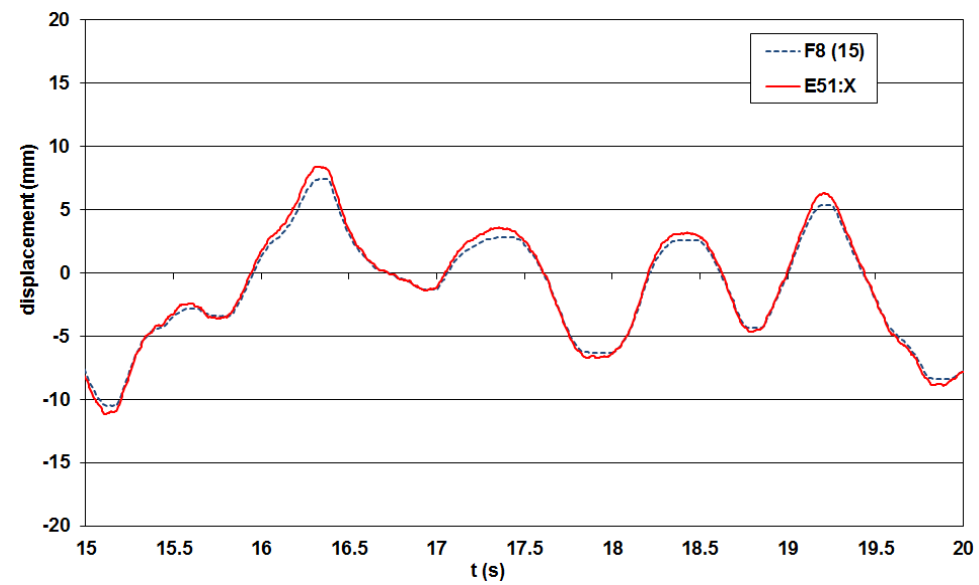

Fig. 10 Comparison between a displacement time-history (detail) in input direction measured by a marker (E51) and by a wire transducer (F8) both located at the same position on the façade

\subsection{Velocity and acceleration}

Velocity and acceleration of each marker were estimated by numerical differentiation of trajectories. As this procedure typically causes a dramatic amplification of data noise, direct measurement by accelerometers is commonly preferred over processing of displacement data. 
Nonetheless, in shaking table testing, maximum values of accelerations typically reach some tenths of $\mathrm{g}$ (occasionally even more than $1 \mathrm{~g}$ ), so that accuracy of the order of $0.01 \mathrm{~g}$ representing an error of less than $10 \%$ can still be adequate to have rough indications on the dynamic behavior of the measured point. Such accuracy can be reached through markers data by combining a numerical convolution differentiation technique associated with a filtering techniques. Classical methods of numerical differentiation based on higher-order central finite differences provide a somewhat low-pass filtering effect (Lyness and Moler 1967). According to such methods a general expression of the first derivative $f^{\prime}$ ' can be written as

$$
f^{\prime}=\frac{1}{\Delta t} \sum_{k=1}^{M} c_{k}\left(f_{k}-f_{1-k}\right)
$$

where $M=(m-1) / 2, \Delta t$ is the time step and $c_{k}$ is the convolution coefficient. Eq. (2) was implemented with the values of $c_{k}$ obtained for the SG filter (Candan and Inan 2014) with the optimal $\mathrm{n}$ and $\mathrm{m}$ values described in the previous section. Fig. 11 shows the FFT of an acceleration noise signal before and after the application of the SG-filter derivation algorithm to highlight the spectral depression induced by this latter. An interesting level of accuracy in velocity and acceleration estimation was achieved. In particular, the estimation of PGV was in very good accordance with the results of usual accelerometer integration techniques (error of $2 \%$ or less for all utilized input spectra, except for only one case in which the error was $7.9 \%$ ), as illustrated in Fig. 12(a).

The even more challenging estimation of PGA with respect to the direct measurements provided by the accelerometer gave errors ranging from $4 \%$ to $12 \%$ depending on the input spectrum, as shown in Fig. 12(c). Finally, the implemented technique was remarkably more effective than the mere application of a standard Butterworth passband filter (4th order with cutoff frequency at $25 \mathrm{~Hz}$ ), which gave PGV errors up to $27.4 \%$ (Fig. 12(b)) and PGA errors from 45 $\%$ to $223 \%$ (Fig. 12(d)).

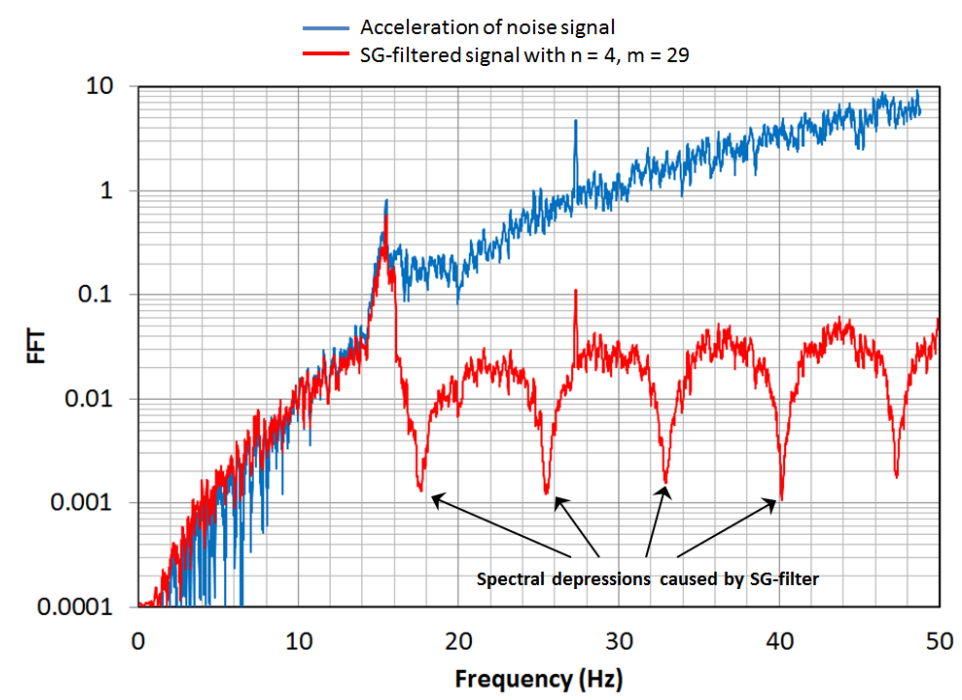

Fig. 11 FFT of acceleration of 3DVision noise signal before (blue line) and after (red line) optimized SG-filter derivation 


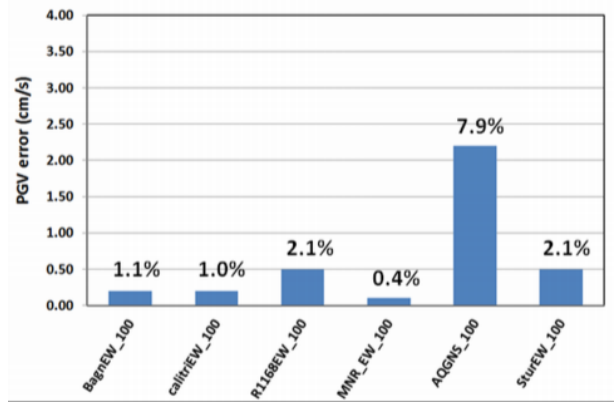

(a) PGV estimation with SG-filter derivation

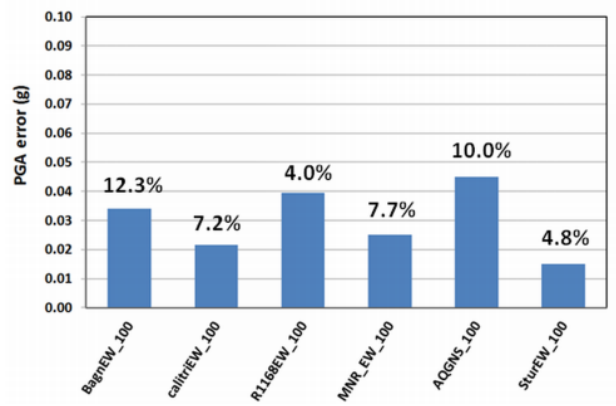

(c) PGA estimation with SG-filter derivation

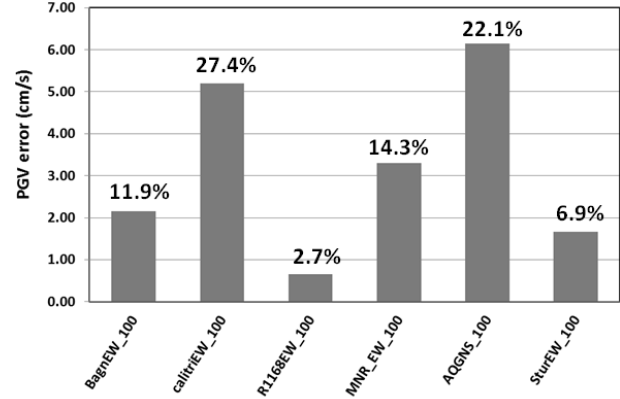

(b) PGV estimation with Butterworth filter

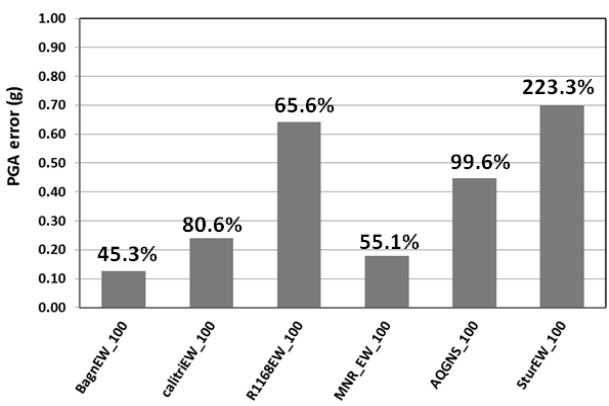

(d) PGA estimation with Butterworth filter

Fig. 12 Markers error in the estimation of PGV and PGA by optimized SG-filter derivation and by standard Butterworth passband filter (4th order with cut-off frequency at $25 \mathrm{~Hz}$ )

\subsection{Detection of dynamic properties through modal analysis}

In order to detect the evolution of the dynamic properties of the specimen during the shaking table tests, the displacement data of the markers were used to perform the modal analysis by enhanced frequency domain decomposition (EFDD) and frequency response function (FRF) techniques. The preliminary FEA helped the identification of modes by EFDD when the resonance amplification was mild. The HVSR technique with a velocimeter carried out on the initial undamaged specimen was used as a further comparison to validate the results from markers data.

\subsubsection{EFDD analysis}

The EFDD was preferred to other OMA techniques on the base of the past experiences with markers data (Roselli et al. 2015) and because it allows to extract modal damping factors as well. The peak picking technique was generally used (Fig. 13(a)), but when the peaks were not clearly identifiable, the comparison between EFDD and FEA modal shapes animations revealed crucial contribution for modes identification. In fact, the use of a large number of markers allowed a good definition of the modal shapes. The first mode, in particular, was easily identified by matching the antiphased oscillation of the markers on rear top of the lateral walls (Fig. 13(b)) with the corresponding nodes of the FE model. Though situated in positions apparently irrelevant to the out-of-plane behavior of the façade, the abovementioned measurement points resulted capable of catching the overall dynamic behavior of the structure. The frequency of the first mode was identified at $8.8 \mathrm{~Hz}$ and the one of the second mode at $15.1 \mathrm{~Hz}$ (Fig. 13(a)). 


\subsubsection{FRF with selected markers}

Shaking table testing data were treated with a multi-input/multi-output (MIMO) technique (Maia and Silva 1998), initially considering all the markers at the base as input points and all the remaining markers placed on the structure as output points. The use of a large number of input and output points provided a smoother and less noisy FRF, exploiting the spectral averaging effect, and made it possible to include nearly all the meaningful modes.

On the other hand, choosing a few selected output points located at positions where a specific modal shape deformations are particularly evident provided an FRF with higher amplification peaks, which made the identification of that mode easier. All this taken into account, as a first step, the modal shapes derived from the preliminary FEA guided the selection of the most appropriate output markers for each mode in MIMO FRF implementation. In particular, the markers data on the façade in $x$ direction revealed prevalently the second mode and indicated a fundamental frequency of $15.4 \mathrm{~Hz}$ (Fig. 14(a)), while markers on rear top lateral walls in y direction (i.e., markers S61 and N64, see Fig. 5(b) and 5(c)) gave clearer indications about the first mode, whose frequency was identified at $8.8 \mathrm{~Hz}$ (Fig. 14(b)).

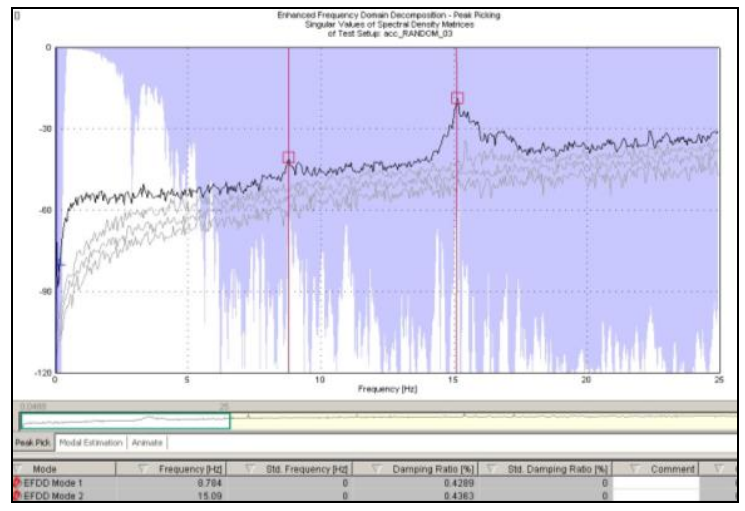

(a) Frequency peak picking

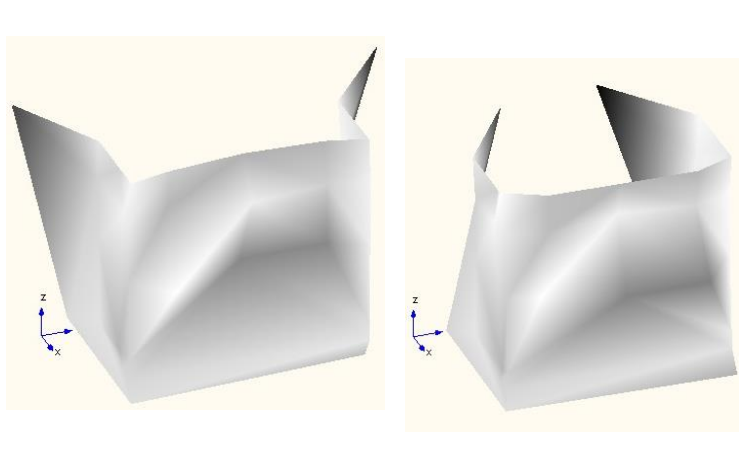

(b) Modal shape animation

Fig. 13 Identification of first mode through EFDD analysis

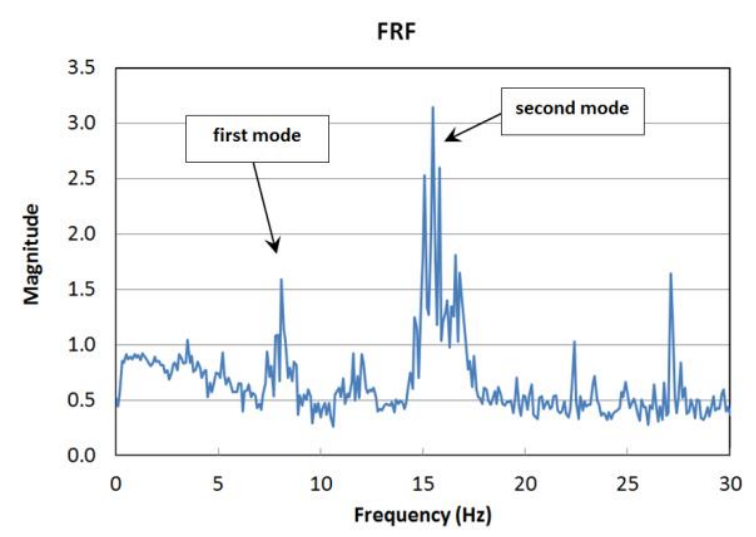

(a) Markers on the façade in $x$

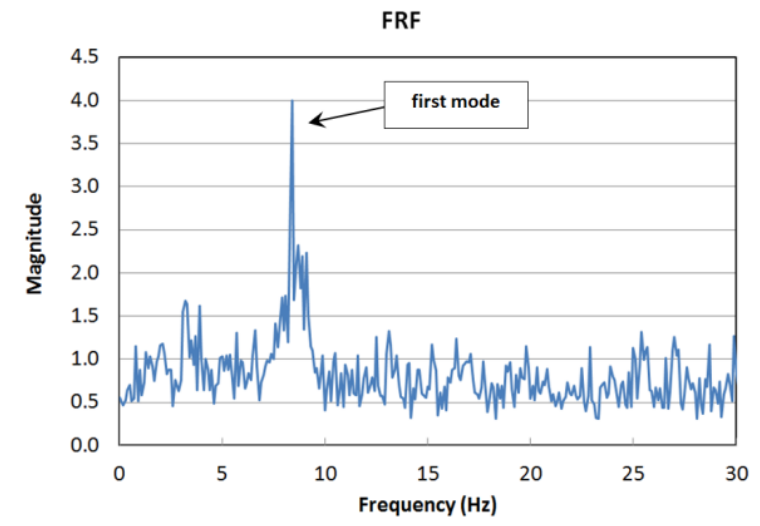

(b) Markers on rear top of lateral walls in $y$

Fig. 14 FRF with selected output markers 


\section{Results}

The unreinforced specimen collapsed under CalitWE signal with a PGA of $0.29 \mathrm{~g}$, corresponding to a $\mathrm{VSI}_{5-16}$ of $1.3 \mathrm{~cm}$. However, structural damage appeared already since test at $\mathrm{VSI}_{5-16}=0.4 \mathrm{~cm}$ and progressed quite steadily during the following steps, as evidenced by the drift in $\mathrm{x}$ of the markers on the façade (Fig. 15) and by the behavior of the lateral connections (Figs. 16, 18 and 19). In particular, the south connection resulted weaker than the north one and gradually opened. Once the north connection also failed, the façade began out-of-plane rocking until final collapse. Both the first and the second modal frequencies shifted downwards with a quasi-parallel trend (Fig. 21(a)), indicating that the stiffness of the specimen decreased similarly in $x$ and $y$ directions.

After reinforcement with SRG, the south connection started opening only at $\mathrm{VSI}_{5-16}=7.0 \mathrm{~cm}$ (Fig. 19) and failure occurred under Nocera Umbra (R1168WE) signal with $1.5 \mathrm{~g}$ of PGA and VSI $_{5-16}=15.9 \mathrm{~cm}$, without a complete out-of-plane overturning, because the strips contained the facade and the lateral connectors held it backwards (Figs. 17 and 18(c)). Such behavior led to the failure mechanism enhanced by the concave permanent deformation of the façade in the final test (Fig. 20) with the formation of various cracks dispersed all over the façade.

The retrofitting with SRG resulted in a limited increase of the stiffness of the structure, as revealed by slightly higher modal frequencies (Fig. 21). As for the second mode, related to the outof-plane deflection of the façade, the frequency increased from $12.4 \mathrm{~Hz}$ to $15.4 \mathrm{~Hz}$ after the installation of the SRG strips (Fig. 21(b)). This result is in good agreement with the dynamic characterization performed with the acceleration time histories recorded by traditional accelerometers, which provided an initial fundamental frequency before and after reinforcement of 13.6 Hz and $16.2 \mathrm{~Hz}$, respectively (De Santis et al. 2015). Both the measurement methods also revealed that the second mode was very stable and decreased remarkably only in the last step when failure occurred.

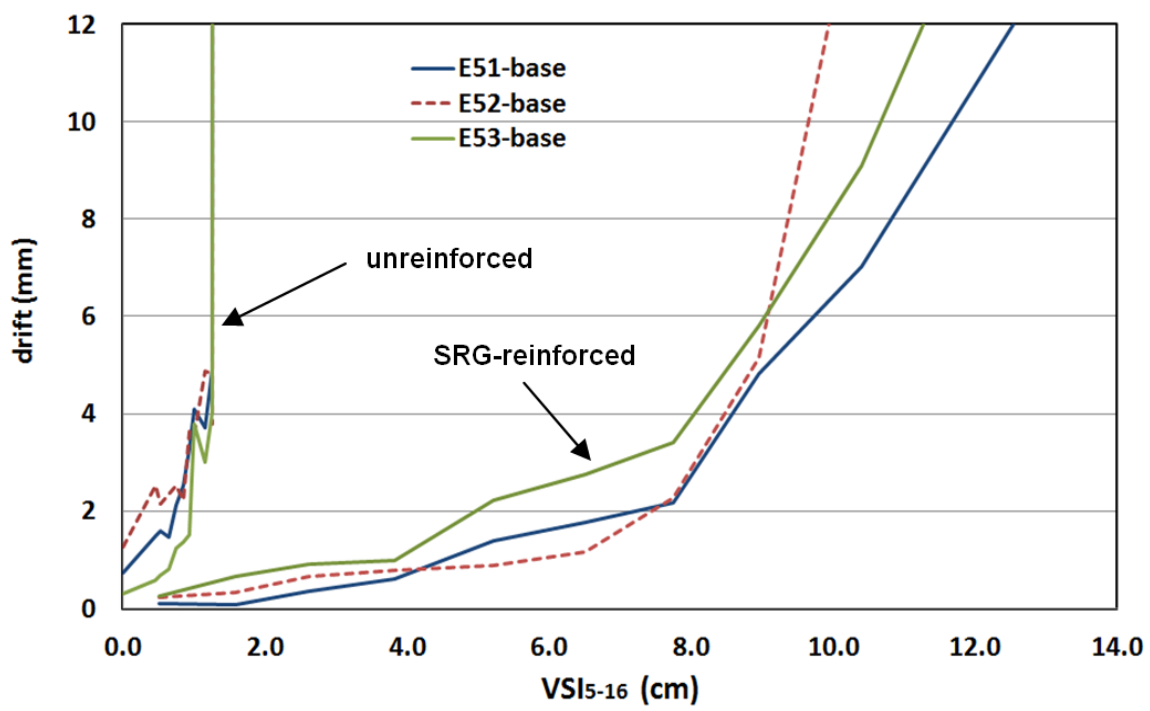

Fig. 15 Relative displacement (drift) in $x$ direction between markers at height $3.2 \mathrm{~m}$ on the façade and the base of the unreinforced and SRG-reinforced specimen 


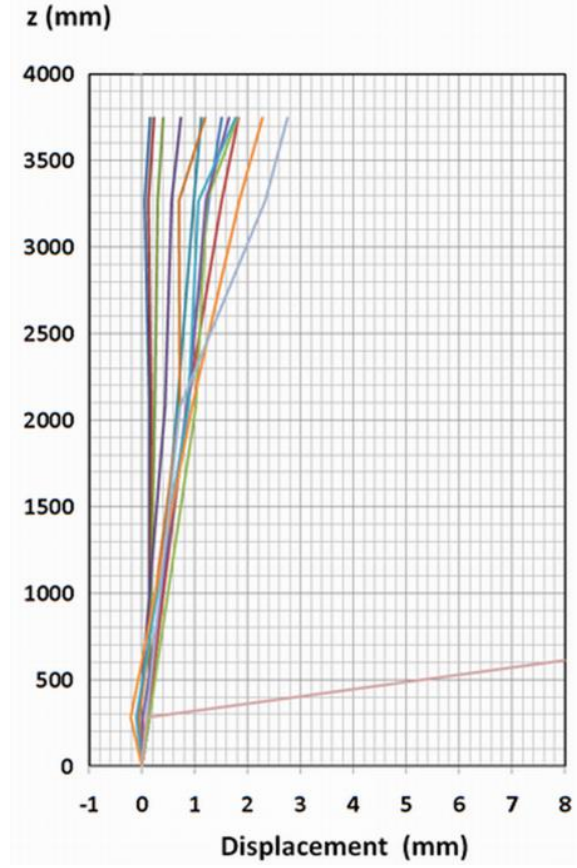

(a) South connection

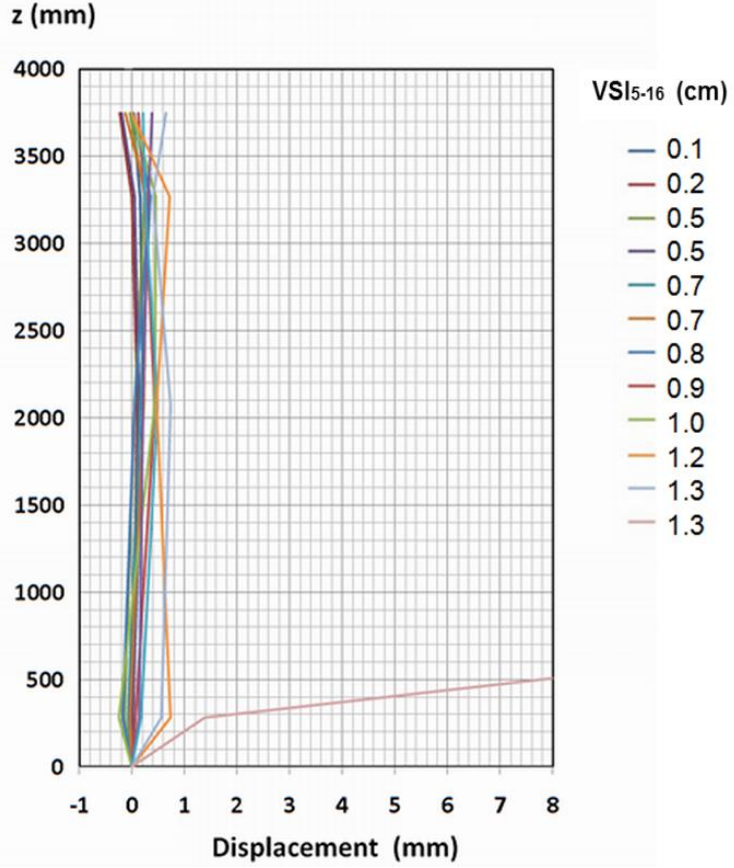

(b) North connection

Fig. 16 Evolution of the lateral connections of the unreinforced specimen throughout the shaking table tests

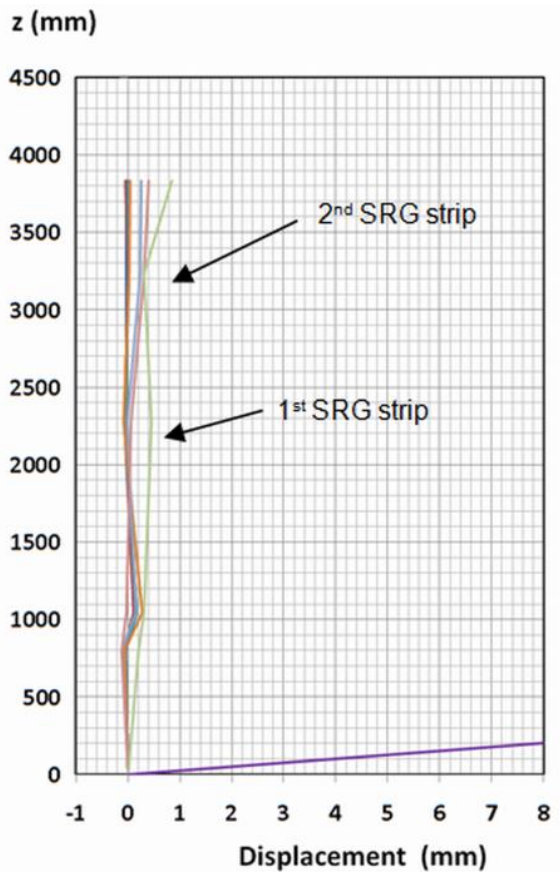

(a) South connection

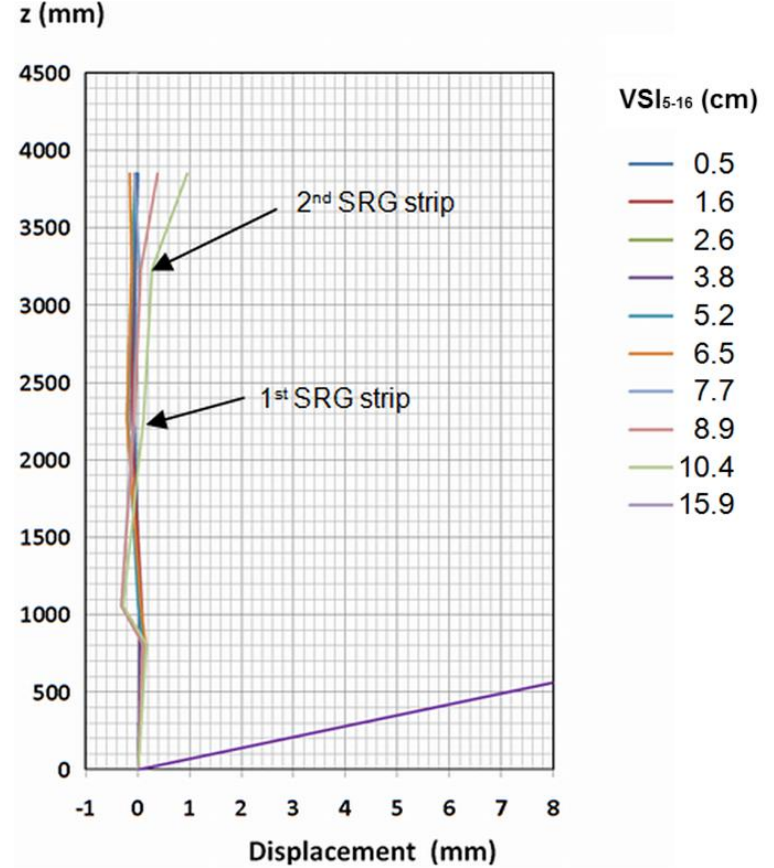

(b) North connection

Fig. 17 Evolution of the lateral connections of the SRG-reinforced specimen throughout the shaking table tests 


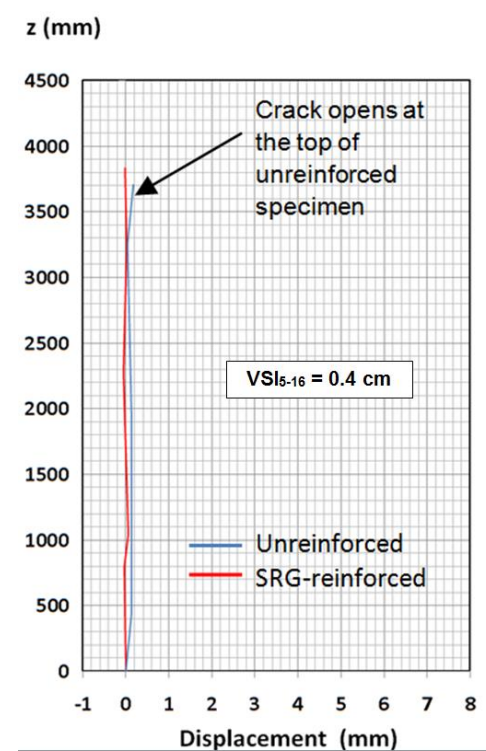

(a) After test at VSI $_{5-16}=0.4 \mathrm{~cm}$

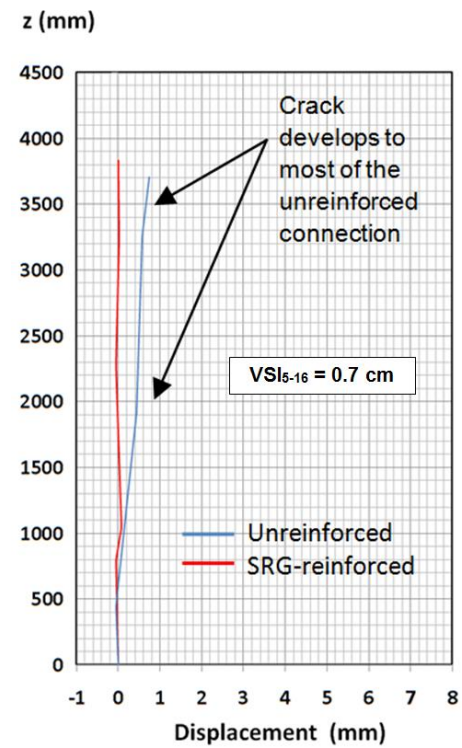

(b) After test at $\mathrm{VSI}_{5-16}=0.7 \mathrm{~cm}$

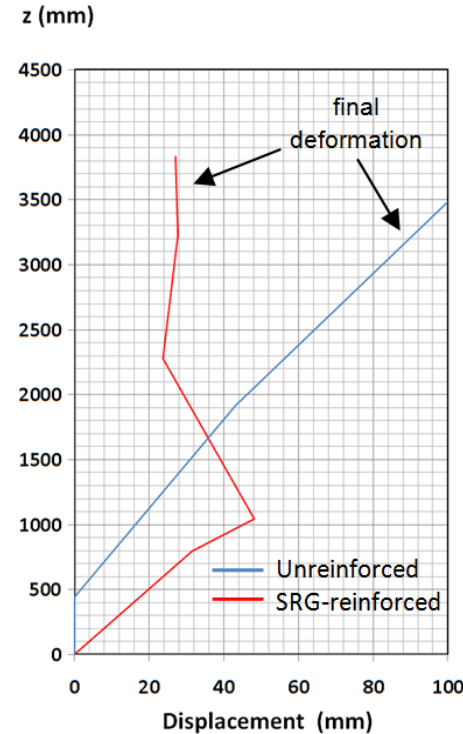

(c) Final deformation

Fig. 18 Comparison between the evolution of the south connection in the specimen unreinforced and with SRG reinforcement

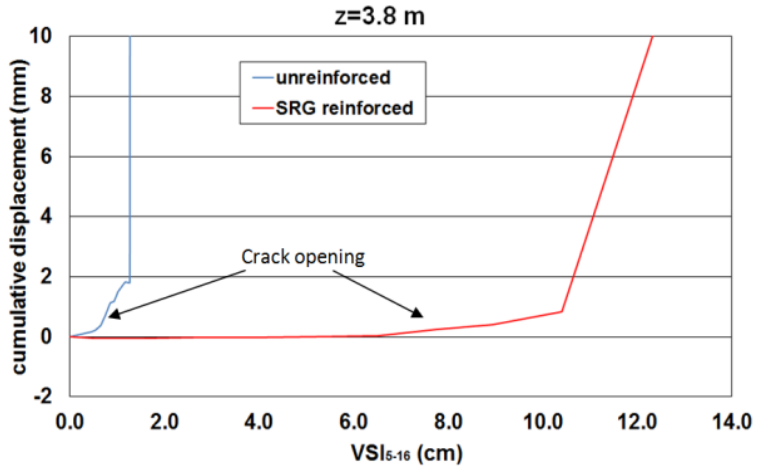

Fig. 19 Progression of crack aperture on top of the south connection throughout the shaking table tests

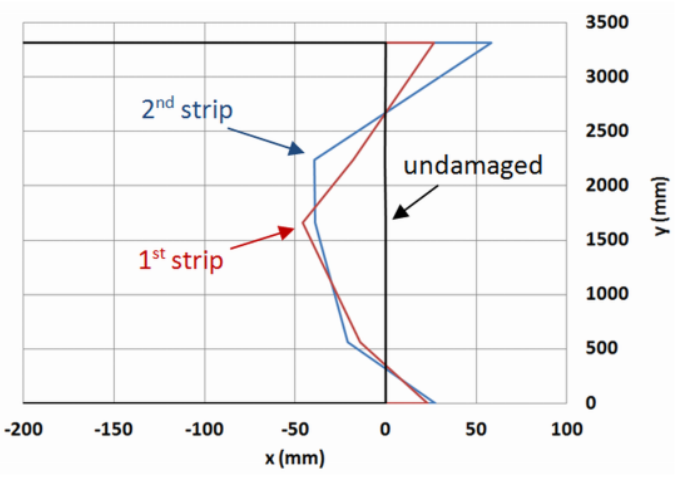

Fig. 20 Permanent deformation at each strip on the façade of the SRG-reinforced specimen at the end of the shaking table tests (plan view) 


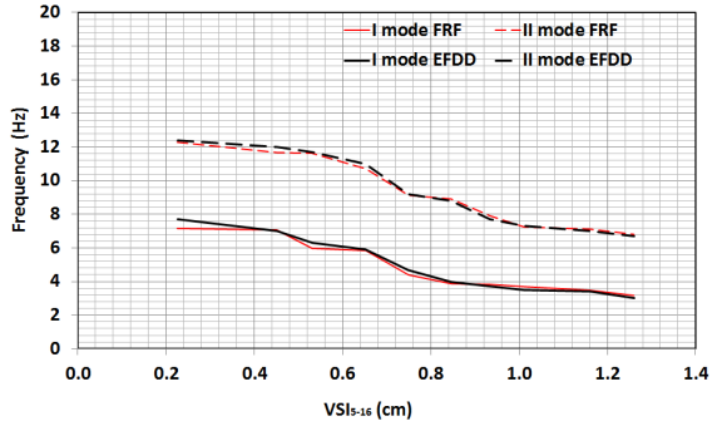

(a) Unreinforced specimen

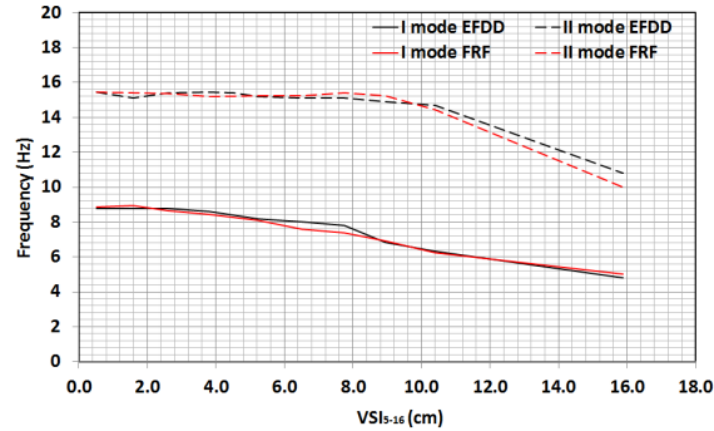

(b) SRG-reinforced specimen

Fig. 21 Frequency shift throughout the shaking table tests

\section{Conclusions}

An unconventional measurement method based on a passive 3D motion capture system was used to analyze shake table tests on a natural-scale masonry structure retrofitted with SRG. A displacement data processing (DDP) method was implemented to achieve an accurate description of the structural response and provide useful information to integrate traditional instrumentation. More specifically, the main conclusions may be summarized as follows.

The use of numerous markers located on the tested specimen permitted the reconstruction of the dynamic 3D displacement field and modal shapes under earthquake motion with great completeness, allowing a deep understanding of the seismic response of masonry walls.

Drifts, cracks opening at wall connections and permanent deformations were directly obtained thanks to a suitable distribution of the passive markers over the specimen.

Marker displacements provided the dynamic properties (modal frequencies and shapes) of the structure through the application of EMA/OMA techniques. In particular, the EFDD and the FRF with MIMO (selecting output markers in accordance with FEM modal shapes) techniques were used and validated for the case under study with a HVSR of velocimeter data acquired on the undamaged specimen. All three used techniques provided analogous results.

The 3DVision set-up was not affected by the range and encumbrance limitations typical of the traditional displacement sensors and, thanks to the use of cheap passive wireless markers on the mock-up, no relevant instrumentation damage was risked during collapse. Moreover, it did not require the building of any stiff frame in front of the façade as a reference for the out-of-plane displacements.

The use of a 3D optical system with suitable procedures for data processing and analysis led to a coherent and solid understanding of the dynamic behavior and of the evolution of the structural damage of the masonry mock-up during the shake table testing. In particular, the obtained results showed that the applied SRG retrofitting system provided the masonry structure with outstandingly improved out-of-plane seismic capacity, limiting the damage at the lateral connections and avoiding the activation of a rocking mechanism with the consequent out-of-plane collapse of the façade.

\section{References}


Al Shawa, O., de Felice, G., Mauro, A. and Sorrentino, L. (2012), "Out-of-plane seismic behaviour of rocking masonry walls", Earthq. Eng. Struct. D., 41(5), 949-968.

Ascione, L., de Felice, G. and De Santis S. (2015), "A qualification method for externally bonded Fibre Reinforced Cementitious Matrix (FRCM) strengthening systems", Compos. Part. B-Eng., 78, 497-506.

Beraldin, J.A., Latouche, C., El-Hakim, S.F. and Filiatrault, A. (2004), "Applications of photo-grammetric and computer vision techniques in shake table testing", Proceedings of the 13th World Conference on Earthquake Engineering (13WCEE), Vancouver, BC, Canada.

Calderini, C., Lagomarsino, S., Rossi, M., De Canio, G., Mongelli, M. and Roselli, I. (2015), "Shaking table tests of an arch-pillars system and design of strengthening by the use of tie-rods", Bull. Earthq. Eng., 13(1), 279-297.

Candan, C. and Inan, H. (2014), "A unified framework for derivation and implementation of Savitzky-Golay filters", Signal Process., 104, 203-211.

De Canio, G., Mongelli, M. and Roselli, I. (2013), "3D motion capture application to seismic tests at ENEA Casaccia research center. 3DVision system and DySCo virtual lab", Wit. Trans. Built. Env., 134, 803-814.

de Felice, G., De Santis, S., Garmendia, L., Ghiassi, B., Larrinaga, P., Lourenço, P.B., Oliveira, D.V., Paolacci, F. and Papanicolaou, C.G. (2014), "Mortar-based systems for externally bonded strengthening of masonry", Mater. Struct., 47(12), 2021-2037.

De Santis, S. and de Felice, G. (2015a), "Tensile behaviour of mortar-based composites for externally bonded reinforcement systems", Compos. Part. B-Eng., 68, 401-413.

De Santis, S. and de Felice, G. (2015b), "Steel reinforced grout systems for the strengthening of masonry structures", Compos. Struct., 134, 533-548.

De Santis, S., De Canio, G., de Felice, G., Malena, M., Mongelli, M. and Roselli, I. (2015), "Seismic performance of masonry walls retrofitted with steel reinforced grout", Earthq. Eng. Struct. Dyn., doi: $10.1002 /$ eqe. 2625.

Elenas, A. (2013), "Intensity parameters as damage potential descriptors of earthquakes", Compos. Meth. Appl. Sci., 22, 327-334.

Gallipoli, M.R., Mucciarelli, M. and Vona, M. (2009), "Empirical estimate of fundamental frequencies and damping for Italian buildings", Earthq. Eng. Struct. Dyn., 38(8), 973-988.

Hartley, R. and Zisserman, A. (2003), Multiple View Geometry in Computer Vision, Cambridge University Press, UK.

Lunghi, F. Pavese, A., Peloso, S., Lanese, I. and Silvestri, D. (2012), "Computer vision system for monitoring in dynamic structural testing", Geotech. Geol. Earthq., 22, 159-176.

Lyness, J.N. and Moler, C.B. (1967), "Numerical differentiation of analytic functions", SIAM J. Numer. Anal., 4(2), 202-210.

Maia, N. and Silva, J. (1998), Theoretical and Experimental Modal Analysis, Research Studies Press, Baldock, UK.

Moeslund, T.B. and Granum, E. (2001), "A survey of computer vision-based human motion capture", Comput. Vis. Image. Und., 81(3), 231-268.

Razavizadeh, A., Ghiassi, B. and Oliveira, D.V. (2014), "Bond behavior of SRG-strengthened masonry units: Testing and numerical modeling", Constr. Build. Mater., 64, 387-397.

Roselli, I., Mongelli, M., Tati, A. and De Canio, G. (2015), "Analysis of 3D motion data from shaking table tests on a scaled model of Hagia Irene, Istanbul", Key Eng. Mater., 624, 66-73.

Savitzky, A. and Golay, M.J.E. (1964), "Smoothing and differentiation of data by simplified least squares procedures", Anal. Chem., 36(8), 1627-1639.

Stephen, G.A., Brownjohn, J.M.W. and Taylor, C.A. (1993), "Measurement of static and dynamic displacement from visual monitoring of the Humber Bridge", Eng. Struct., 15(3), 197-208.

Valluzzi, M.R., Modena, C. and de Felice, G. (2014), "Current practice and open issues in strengthening historical buildings with composites", Mater. Struct., 47(12), 1971-1985.

Vicon iQ System Reference-Volume II (2006), Motion capture production and control software, Oxford.

Ye, L., Ma, Q., Miao, Z., Guan, H. and Zhuge, Y. (2013), "Numerical and comparative study of earthquake intensity indices in seismic analysis", Struct. Des. Tall. Spec., 22(4), 362-381. 
Yoneyama, S., Kitagawa, A., Iwata, S., Tani, K. and Kikuta, H. (2007), "Bridge deflection measurement using digital image correlation", Exp. Techniq., 31(1), 34-40.

Webster, J.G. (1999), The Measurement, Instrumentation and Sensors Handbook, CRC Press-IEEE Press.

$S A$ 